Case Report

\title{
Posterior Reversible Encephalopathy Syndrome Associated with Tacrolimus in Cardiac Transplantation
}

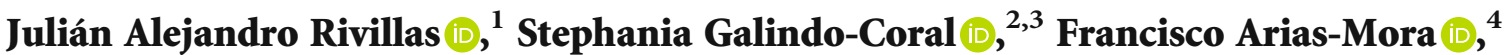 \\ Juan David Lopez-Ponce de Leon $\mathbb{D}^{1},{ }^{2}$ Noel Alberto Florez-Alarcón $\mathbb{D}^{\mathbb{D}},{ }^{2}$ Pastor Olaya-Rojas $\mathbb{D},{ }^{2}$ \\ and Juan Esteban Gomez-Mesa ${ }^{2}{ }^{2}$
}

\author{
${ }^{1}$ Resident of Neurology, Universidad Icesi, Cali, Colombia \\ ${ }^{2}$ Cardiology Department, Fundación Valle del Lili Hospital Universitario, Cali, Colombia \\ ${ }^{3}$ Clinical Research Center, Fundación Valle del Lili Hospital Universitario, Cali, Colombia \\ ${ }^{4}$ Neurology Department, Fundación Valle del Lili Hospital Universitario, Cali, Colombia
}

Correspondence should be addressed to Juan Esteban Gomez-Mesa; juan.gomez.me@fvl.org.co

Received 12 March 2021; Accepted 10 June 2021; Published 25 June 2021

Academic Editor: Yigit Canga

\begin{abstract}
Copyright ( 92021 Julián Alejandro Rivillas et al. This is an open access article distributed under the Creative Commons Attribution License, which permits unrestricted use, distribution, and reproduction in any medium, provided the original work is properly cited.
\end{abstract}

\begin{abstract}
Background. Neurological complications occur between 50 and $70 \%$ of patients with heart transplantation, including cerebrovascular events, infections, seizures, encephalopathy, and neurotoxicity due to pharmacological immunosuppression. Mortality associated with cerebrovascular complications is $7.5 \%$ in the first 30 days and up to $5.3 \%$ after the first month and up to the first year after transplantation. Case Reports. Three heart-transplanted patients ( 2 men and 1 woman) treated with tacrolimus were identified. They presented with posterior reversible encephalopathy syndrome on days 5 , 6 , and 58 posttransplantation, respectively. In these reported cases, no sequelae were observed at 6 months follow-up. Conclusions. Posterior reversible encephalopathy syndrome as a neurological complication in patients with HT occurred early after the procedure. Early diagnosis and treatment might reduce the risk of serious complications and mortality.
\end{abstract}

\section{Background}

Heart transplantation (HT) is a therapeutic option in patients with advanced and refractory heart failure. In Latin America, this procedure has been performed in more than 8,000 patients, in more than 85 institutions in 13 Latin American countries since $1968[1,2]$. The current worldwide survival rate is up to $90 \%$ for the first year, with a median survival of 14 years. The patient's quality of life improves significantly, and up to $30 \%$ of them may reintegrate into working life [3]. After HT, different complications may occur, affecting the survival and functionality of patients, such as graft rejection, infections, neoplasms, high blood pressure, kidney disease, and neurological complications $[4,5]$.

Neurological complications occur between $50 \%$ and $70 \%$ of patients with HT when transient and mild effects are included. Most may occur within the first 30 days after the procedure and include cerebrovascular events, infections, seizures, encephalopathy, and neurotoxicity due to immunosuppressive medication. Neurological involvement is of particular concern because of its impact on patients' functional prognosis and survival $[6,7]$. The most severe neurological complications are ischemic stroke followed by infection. Mortality associated with cerebrovascular complications is $7.5 \%$ in the first 30 days and up to $5.3 \%$ after the first month and up to the first year after transplantation. It can be as high as $20 \%$ in cases of opportunistic infections and cerebrovascular events $[5,8-10]$.

The most frequently maintained immunosuppressive agents used in heart transplants are corticosteroids, calcineurin inhibitors, and antimetabolites. Corticosteroids induce commonly acute neuropsychiatric symptoms including delirium, sleep disorders, depression, and cognitive decline. Cyclosporine and tacrolimus are both calcineurin inhibitors 
TABLE 1: Description of patients with PRES after heart transplant.

\begin{tabular}{|c|c|c|c|}
\hline & Case 1 & Case 2 & Case 3 \\
\hline Gender & Male & Male & Female \\
\hline Age (years) & 27 & 67 & 29 \\
\hline Etiology of HF & Becker muscular dystrophy & Ischemic heart disease & Chagas' heart disease \\
\hline $\begin{array}{l}\text { Onset of PRES } \\
\text { symptoms (days) }\end{array}$ & 6 & 5 & 58 \\
\hline Symptoms & $\begin{array}{l}\text { Decreased visual acuity, } \\
\text { generalized tonic-clonic seizures, } \\
\text { altered level of consciousness }\end{array}$ & $\begin{array}{l}\text { Blurred vision generalized } \\
\text { tonic-clonic seizures, altered } \\
\text { level of consciousness }\end{array}$ & $\begin{array}{l}\text { Blurry vision generalized } \\
\text { tonic-clonic seizures, altered } \\
\text { level of consciousness, } \\
\text { severe headache }\end{array}$ \\
\hline Previous drugs & $\begin{array}{l}\text { Tacrolimus MMF, } \\
\text { methylprednisolone, } \\
\text { TMP/SMX, acyclovir, } \\
\text { vancomycin }\end{array}$ & $\begin{array}{l}\text { Tacrolimus MMF, } \\
\text { methylprednisolone, } \\
\text { TMP/SMX, acyclovir, } \\
\text { vancomycin, ceftriaxone }\end{array}$ & $\begin{array}{c}\text { Tacrolimus MMF, prednisone, } \\
\text { TMP/SMX, acyclovir, } \\
\text { diltiazem, losartan }\end{array}$ \\
\hline Hemoglobin (mg/dl) & 9.0 & 10 & 8.5 \\
\hline Leukocytes (cel/ml) & 6,470 & 8,540 & 14,130 \\
\hline Platelets (cel/ml) & 130,000 & 140.000 & 441,000 \\
\hline Creatinine (mg/dl) & 0,9 & 0,8 & 0,88 \\
\hline Sodium (mEq/l) & 141 & 139 & 135 \\
\hline Potassium (mEq/l) & 3.9 & 4.0 & 5.97 \\
\hline Glycemia (mg/dl) & 138 & 165 & 145 \\
\hline Tacrolimus (ng/dl) & 2.6 & 8.9 & 17.4 \\
\hline Brain MR & $\begin{array}{c}\text { Bilateral and symmetrical } \\
\text { parietal and occipital } \\
\text { cortical-subcortical hyperintensities } \\
\text { in the FLAIR and T2 } \\
\text { sequences (Figure 1) }\end{array}$ & $\begin{array}{l}\text { Asymmetric cortical } \\
\text { hyperintensities in the } \\
\text { parietal and occipital } \\
\text { lobes (Figure 2) }\end{array}$ & $\begin{array}{c}\text { Hyperintense lesions } \\
\text { of posterior cortical and } \\
\text { subcortical predominance } \\
\text { without abnormal enhancements } \\
\text { with the contrast agent (Figure 3) }\end{array}$ \\
\hline Management & $\begin{array}{l}\text { Discontinuing tacrolimus, starting } \\
\text { cyclosporine, levetiracetam }\end{array}$ & $\begin{array}{l}\text { Discontinuing tacrolimus, } \\
\text { starting cyclosporine, } \\
\text { levetiracetam }\end{array}$ & $\begin{array}{l}\text { Discontinuing tacrolimus, starting } \\
\text { cyclosporine, levetiracetam }\end{array}$ \\
\hline $\begin{array}{l}\text { Recurrence of } \\
\text { symptoms at } 6 \text { months }\end{array}$ & None & None & None \\
\hline
\end{tabular}

HF: heart failure; PRES: posterior reversible encephalopathy syndrome; HT: heart transplantation; MMF: mycophenolate mofetil; TMP/SMX: trimethoprimsulfamethoxazole; NMR: nuclear magnetic resonance.

and can induce encephalopathy, seizures, akinetic mutism, and posterior reversible encephalopathy syndrome. Mycophenolate mofetil and azathioprine are antimetabolites. Mycophenolate mofetil does not have a significant direct neurotoxicity, but it may cause headaches on first doses. Azathioprine is rarely used for heart transplantation [6].

\section{Clinical Case Reports}

Three cases of HT patients with PRES associated with the use of tacrolimus observed at different times after the procedure are described in a cohort of 223 heart transplant patients in a Colombian hospital. Clinical and radiological information is in Table 1 and Figures 1-3.

\section{Discussion}

PRES was initially described in 1996 [11] and has ever since been associated with clinical conditions such as high blood pressure, eclampsia, infections, autoimmune diseases, and the use of immunosuppressive drugs. The underlying patho- physiological mechanisms are not clear, but differences have been described in the vascular sympathetic innervation of the anterior and posterior brain circulation with a variable degree in the self-regulation capacity in the presence of external noxae as changes in cerebral perfusion pressure, microangiopathy, and toxic effects (i.e., tacrolimus). These tissue insults favor vasogenic edema in the parietal and occipital lobes occur [12]. In PRES associated with CI, vasoconstricting effects and direct endothelial damage have been described, which cause capillary leakage due to disruption of the blood-brain barrier, which ultimately causes cerebral vasogenic edema [13]. This effect is thought to be related to an intrinsic factor of inhibition of calcineurin widely expressed in the central nervous system. The absence of hypertension crisis and normal serum calcineurin values at diagnosis in reported cases in this article supports that hypothesis. The occurrence of PRES after heart transplantation is typically on the first 30 days after surgery with great variation among studies [14]. In published cases reviewed for this article, we found a median of 14 days after heart transplantation. Two of the cases presented here were below 


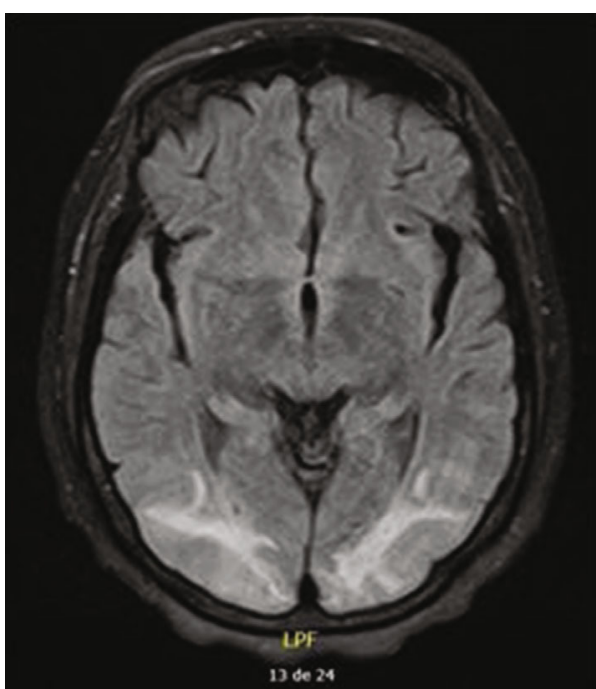

(a)

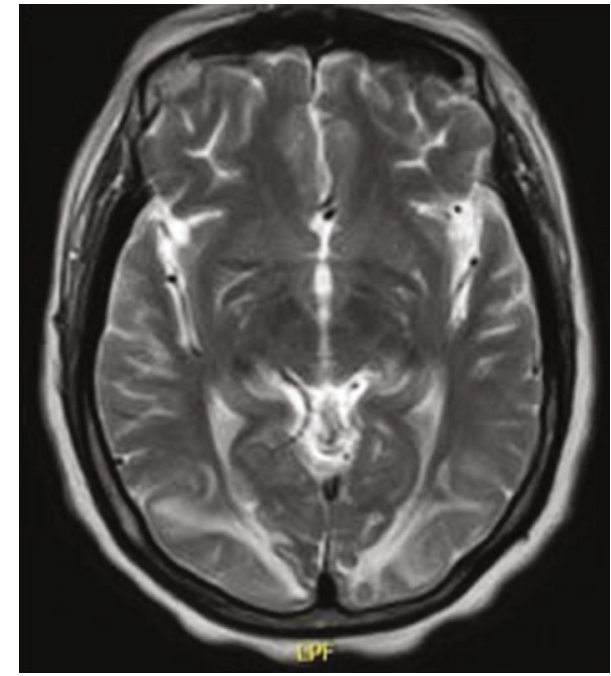

(b)

FIGURE 1: Brain MR of case 1. (a) Fluid-attenuated inversion recovery sequence showing occipital hyperintensities in occipital gyri. (b) T2weighted sequence of the same patient showing hyperintensities in the occipital lobe.

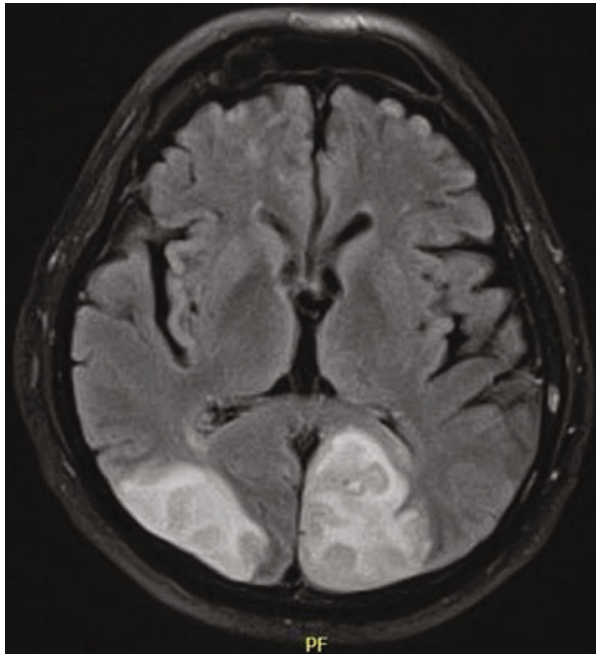

(a)

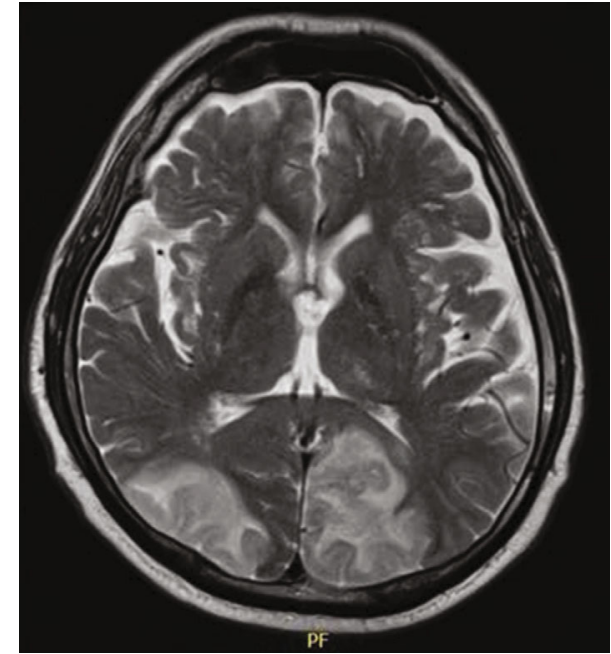

(b)

FIgURE 2: Brain MR of case 2. (a) Fluid-attenuated inversion recovery sequence showing extensive bilateral asymmetrical occipital hyperintensities in the occipital lobe and (b) its representation on T2-weighted sequence.

this mean time (Table 2). Since most of the reported cases are single-center case series, it is difficult to estimate the true incidence of the problem. Available data indicate that the incidence of PRES syndrome after solid organ transplantation was estimated to be between $1 \%$ and $6 \%$ [15], but more recent studies estimated it at $0.49 \%$ to $1.6 \%$ for heart transplants [16] At the end of 2020, our group had performed 223 heart transplants, so we calculate a cumulative incidence of 1.3 cases per 100 transplants since the start of the program in 1994.

3.1. Clinical Features, Imaging, and Histological Findings. PRES is characterized by an alteration of the level of consciousness, seizures, headache, visual disturbances, neurological deficit, and status epilepticus. Fugate and Rabinstein [17] proposed a 7-category list for patients with PRES: encephalopathy, seizure, headache, visual disturbance, focal neurological deficits, status epilepticus, and nausea/vomiting. All of the patients reported by us lacked the three latter. The typical triad of headache, visual disturbances, and seizures was present in all three reported cases. This triad seems to be present in $77 \%$ of cases according to previous studies. Other common symptom combination is seizures/encephalopathy (38\%), seizures/headache (22.5\%), and seizures/visual disturbances (14\%) [17].

Brain resonance usually reports bilateral and asymmetric hyperintensities in T2-FLAIR sequences of the occipital and parietal regions, but transient lesions can also be found in the anterior region, cerebellum, centrum semiovale, pons, and hippocampus. Also, coexistent ischemic lesions can be 


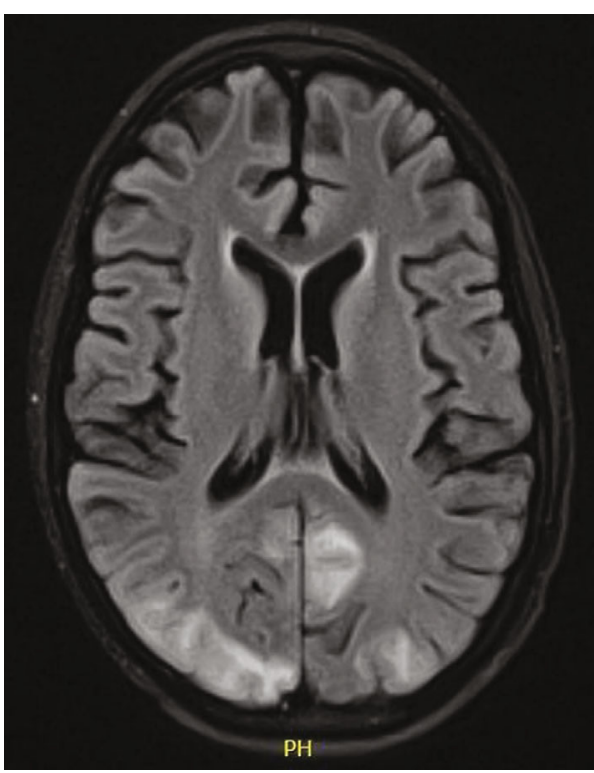

(a)

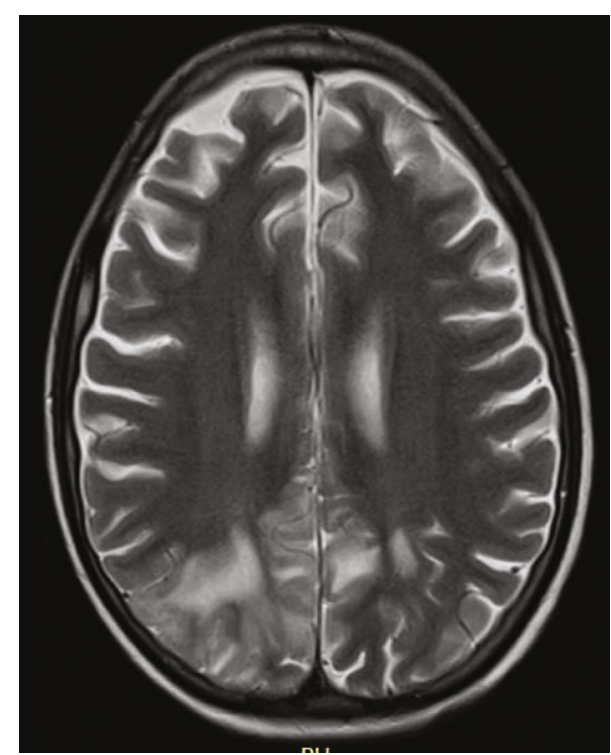

(b)

FIGURE 3: Brain MR of case 3. (a) Fluid-attenuated inversion recovery sequence showing occipitoparietal hyperintensities and (b) its representation in T2-weighted sequence.

present [18]. All reported cases showed typical brain MRI findings, but case 2 presented asymptomatic lesions in the frontal lobe. These findings may support a hypothesis of global alteration of the blood-brain barrier with posterior predominance. No other atypical or hemorrhagic lesions such as those described by McKinney et al. were found [19].

Histopathological findings of cellular edema, disruption of the blood-brain barrier, and, in some cases, necrosis are also observed [20]. These findings help to understand the pathophysiology of the disease but are rarely used in clinical practice. No histopathology information is available for our cases.

3.2. Risk Factors. The onset of symptoms usually occurs during the first month posttransplantation and rarely after the first year despite the chronic use of CI and dose titration during follow-up. The immediate postsurgical period and the following 30 days are critical, since the patient has been suffering from a chronic and debilitating disease with a significant compromise of the functional reserve and subsequently undergoes a major surgery with varying degrees of hemodynamic compromise, tissue hypoperfusion, and administration of immunosuppressive drugs. The reason for the greater incidence of PRES within the first 30 days is not known, but it may be favored by all the factors mentioned above [17]. Two of the reported cases developed PRES during the first 30 days and the other after 58 days, which was associated with a longer hospitalization time and evidence of graft dysfunction in the mediate the postoperative period. Other risk factors frequently reported as hemorrhage and diffusion restriction were not found in our patients [21].

3.3. PRES and Calcineurin Inhibitors. The harmful effects of CI on the endothelium do not seem to be dose-dependent, since many reported cases show normal serum tacrolimus levels at the time of PRES diagnosis (Table 1). That is the case of reported patients. They also lacked a history of hypertensive crises. Similar findings are reported by Song et al. [22]. In contrast, the systematic review performed by this same author reveals a history of hypertension in $69 \%$ of patients with PRES after transplantation. The reports of patients with cyclosporine-associated neurotoxicity included headache, seizures, and encephalopathy, and nausea is not necessarily associated with radiological findings of PRES [23, 24]. A trend toward an earlier occurrence and higher likelihood of PRES in the presence of normal drug levels in transplant recipients receiving cyclosporine than those receiving tacrolimus (median time to onset; 12 vs. 26 days and 40\%, 8/20 vs. $25.8 \%, 8 / 31)$ [22].

3.4. PRES Treatment and Prognosis. Despite the lack of a general guideline, switching from tacrolimus to cyclosporine is a common measure in the cases published to date. Cyclosporine is effective in preventing organ rejection but has also a risk of causing PRES and other types of neurotoxicity [14]. However, given its high availability in developing countries, it is frequently used in cases of intolerance or adverse effect with other calcineurin inhibitors. Remarkably, in the sixmonth follow-up, our patients did not present relapse or any other type of neurotoxicity. It is feasible to think that the immunosuppressant is a factor in the early stages after surgery that contributes to the development of PRES but it is not the only cause. Implant rejections were not reported. Consequently, this strategy may seem to be safe and effective for the management of tacrolimus-associated PRES [25-27]. Other approaches include switching to sirolimus, everolimus, mycophenolate mofetil, or hydrocortisone and lowering the dose of immunosuppressive agent. Classically, a low incidence of sequelae, mortality, and recurrence has been described, as evidenced in these three cases. However, some 
TABLE 2: Reported cases compared with reported cases in Literature.

\begin{tabular}{|c|c|c|c|c|c|c|c|}
\hline Ref & Sex & Age (years) & Days post-HT & Tacrolimus & Steroids & MMF & Sequelae \\
\hline \multicolumn{8}{|c|}{ Reported cases } \\
\hline- & $\mathrm{M}$ & 27 & 6 & Yes & Yes & Yes & No \\
\hline- & M & 67 & 5 & Yes & Yes & Yes & No \\
\hline- & $\mathrm{F}$ & 29 & 58 & Yes & Yes & Yes & No \\
\hline \multicolumn{8}{|c|}{ Cases in literature } \\
\hline 1 & $\mathrm{~F}$ & 68 & 14 & Yes & No & Yes & No \\
\hline 1 & M & 19 & 44 & Yes & No & Yes & No \\
\hline 2 & $\mathrm{~F}$ & 26 & 7 & Yes & Yes & Yes & No \\
\hline 2 & M & 33 & 15 & Yes & Yes & Yes & No \\
\hline 3 & M & 52 & 8 & Yes & Yes & Yes & Yes \\
\hline 4 & M & 37 & 16 & Yes & Yes & Yes & No \\
\hline 5 & $\mathrm{~F}$ & 32 & 5 & Yes & Yes & Yes & No \\
\hline 6 & $\mathrm{~F}$ & 30 & 45 & No & Yes & Yes & No \\
\hline 7 & $\mathrm{~F}$ & 22 & 5 & Yes & No & Yes & No \\
\hline 8 & M & 10 & 10 & Yes & Yes & Yes & No \\
\hline 9 & $\mathrm{~F}$ & 54 & 14 & Yes & No & Yes & No \\
\hline 10 & M & 18 & 150 & Yes & Yes & Yes & No \\
\hline 11 & $\mathrm{~F}$ & 20 & 60 & Yes & Yes & Yes & No \\
\hline 12 & M & 10 & 4 & Yes & Yes & Yes & No \\
\hline 13 & $\mathrm{M}$ & 12 & 4 & Yes & Yes & Yes & No \\
\hline
\end{tabular}

Ref: reference; HT: heart transplantation; MMF: mycophenolate mofetil.

reports report mortality and neurological sequelae as high as $15 \%$ especially when it is not identified and treated early and appropriately [28] (Table 2).

\section{Conclusions}

Neurological complications as PRES in HT patients can occur early after the procedure. Early diagnosis and treatment reduce the risk of more serious outcomes and associated mortality. CI-associated PRES in HT patients is a neurological complication that should be suspected when early "typical manifestations" of an altered level of consciousness, visual disturbances, and seizures appear. The timely diagnosis and treatment of events, change of immunosuppressive therapy to cyclosporine, and multidisciplinary follow-up could reduce the incidence of sequelae.

\section{Abbreviations}

$\begin{array}{ll}\text { CI: } & \text { Calcineurin inhibitors } \\ \text { HF: } & \text { Heart failure } \\ \text { HT: } & \text { Heart transplantation } \\ \text { MMF: } & \text { Mycophenolate mofetil } \\ \text { NMR: } & \text { Nuclear magnetic resonance } \\ \text { PRES: } & \text { Posterior reversible encephalopathy syndrome } \\ \text { TMP/SMX. } & \text { Trimethoprim-sulfamethoxazol. }\end{array}$

TMP/SMX: Trimethoprim-sulfamethoxazol.

\section{Data Availability}

No data were used to support this study.

\section{Conflicts of Interest}

The authors of this manuscript have no conflicts of interest to disclose.

\section{References}

[1] K. Osorio, Informe anual Red de Donación y Trasplantes, Colombia, National Health Institute of Colombia, 2016.

[2] M. Kittleson and J. Kobashigawa, "Cardiac Transplantation: Current Outcomes and Contemporary Controversies," JACC: Heart Failure, vol. 5, no. 12, pp. 857-868, 2017.

[3] R. Dhar, "Neurologic complications of transplantation," Neurocritical Care, vol. 28, no. 1, pp. 4-11, 2018.

[4] A. A. Pruitt, "Neurologic complications of transplantation," CONTINUUM: Lifelong Learning in Neurology, vol. 23, pp. 802-821, 2017.

[5] L. H. Lund, K. K. Khush, W. S. Cherikh et al., "The Registry of the International Society for Heart and Lung Transplantation: Thirty-fourth Adult Heart Transplantation Report-2017; Focus Theme: Allograft ischemic time," The Journal of Heart and Lung Transplantation, vol. 36, no. 10, pp. 1037-1046, 2017.

[6] M. Pizzi and L. Ng, "Neurologic complications of solid organ transplantation," Neurologic Clinics, vol. 35 , no. 4, pp. 809823, 2017.

[7] M. Acampa, P. E. Lazzerini, F. Guideri, R. Tassi, and G. Martini, "Ischemic stroke after heart transplantation," Journal of Stroke, vol. 18, no. 2, pp. 157-168, 2016.

[8] A. Heroux and S. V. Pamboukian, "Neurologic aspects of heart transplantation," Handbook of Clinical Neurology, vol. 121, pp. 1229-1236, 2014. 
[9] D. van de Beek, W. Kremers, R. C. Daly et al., "Effect of neurologic complications on outcome after heart transplant," Archives of Neurology, vol. 65, no. 2, pp. 226-231, 2008.

[10] F. Pérez-Miralles, J. C. Sánchez-Manso, L. Almenar-Bonet, T. Sevilla-Mantecón, L. Martínez-Dolz, and J. J. VílchezPadilla, "Incidence of and risk factors for neurologic complications after heart transplantation," Transplantation Proceedings, vol. 37, no. 9, pp. 4067-4070, 2005.

[11] J. Hinchey, C. Chaves, B. Appignani et al., "A reversible posterior leukoencephalopathy syndrome," The New England Journal of Medicine, vol. 334, no. 8, pp. 494-500, 1996.

[12] W. Bartynski, "Posterior reversible encephalopathy syndrome, part 2: controversies surrounding pathophysiology of vasogenic edema," AJNR. American Journal of Neuroradiology, vol. 29, no. 6, pp. 1043-1049, 2008.

[13] A. S. Barbas, A. S. Rege, A. W. Castleberry et al., "Posterior reversible encephalopathy syndrome independently associated with tacrolimus and sirolimus after multivisceral transplantation," American Journal of Transplantation, vol. 13, no. 3, pp. 808-810, 2013.

[14] M. H. Harirchian, M. Ghaffarpour, M. Tabaeizadeh, and B. Siroos, "Immunosuppressive drugs, an emerging cause of posterior reversible encephalopathy syndrome: case series," Journal of Stroke and Cerebrovascular Diseases, vol. 24, no. 8, pp. e191-e195, 2015.

[15] A. B. Jain, J. J. Fung, S. Todo et al., "One thousand consecutive primary orthotopic liver transplants under FK 506: survival and adverse events," Transplantation Proceedings, vol. 27, no. 1, pp. 1099-1104, 1995.

[16] R. Wong, G. Z. Beguelin, M. de Lima et al., "Tacrolimus-associated posterior reversible encephalopathy syndrome after allogeneic haematopoietic stem cell transplantation," British Journal of Haematology, vol. 122, no. 1, pp. 128-134, 2003.

[17] J. E. Fugate and A. A. Rabinstein, "Posterior reversible encephalopathy syndrome: clinical and radiological manifestations, pathophysiology, and outstanding questions," Lancet Neurology, vol. 14, no. 9, pp. 914-925, 2015.

[18] B. Gao, C. Lyu, A. Lerner, and A. M. McKinney, "Controversy of posterior reversible encephalopathy syndrome: what have we learnt in the last 20 years?," Journal of Neurology, Neurosurgery \& Psychiatry, vol. 89, no. 1, pp. 14-20, 2018.

[19] A. M. McKinney, J. Short, C. L. Truwit et al., "Posterior reversible encephalopathy syndrome: incidence of atypical regions of involvement and imaging findings," American Journal of Roentgenology, vol. 189, no. 4, pp. 904-912, 2007.

[20] N. Willard, J. M. Honce, and B. K. Kleinschmidt-DeMasters, "PRES: review of histological features," Journal of Neuropathology and Experimental Neurology, vol. 77, no. 2, pp. 100$118,2018$.

[21] Z. Chen, G. Zhang, A. Lerner, A. Wang, G. Bo, and J. Liu, "Risk factors for poor outcome in posterior reversible encephalopathy syndrome: systematic review and meta-analysis," Quantitative Imaging in Medicine and Surgery, vol. 8, no. 4, pp. 421-432, 2018.

[22] T. Song, Z. Rao, Q. Tan et al., "Calcineurin inhibitors associated posterior reversible encephalopathy syndrome in solid organ transplantation report of 2 cases and literature review," Medicine, vol. 95, no. 14, article e3173, 2016.

[23] M. M. Burnett, C. P. Hess, J. P. Roberts, N. M. Bass, V. C. Douglas, and S. A. Josephson, "Presentation of reversible posterior leukoencephalopathy syndrome in patients on calcine- urin inhibitors," Clinical Neurology and Neurosurgery, vol. 112, no. 10, pp. 886-891, 2010.

[24] M. H. Ch, F. Alicia Núñez, L. Tomas Mesa, H. Raúl Escobar, C. Francisco Barriga, and L. Isidro Huete, "Leucoencefalopatía reversible posterior: cuatro casos clínicos," Revista Médica de Chile, vol. 136, pp. 93-98, 2008.

[25] Y. Kumai, O. Seguchi, T. Sato et al., "Reversible cerebral vasoconstriction syndrome after heart transplantation: a case report," Transplantation Proceedings, vol. 49, no. 10, pp. 2415-2418, 2017.

[26] A. Kapoor, E. Birks, A. Lenneman, and K. McCants, "Posterior reversible encephalopathy syndrome after heart transplantation: diagnosis and immunosuppressive therapy," Texas Heart Institute Journal, vol. 44, no. 3, pp. 205-208, 2017.

[27] R. Ramirez, P. R. Muskula, and M. P. Everley, "Posterior reversible encephalopathy. syndrome after orthotopic heart transplantation: a case report," American Journal of Case Reports, vol. 18, pp. 487-490, 2017.

[28] C. Roth and A. Ferbert, "Posterior reversible encephalopathy syndrome: long-term follow-up," Journal of Neurology, Neurosurgery, and Psychiatry, vol. 81, no. 7, pp. 773-777, 2010. 